\title{
LOS SUPUESTOS DE LA RESPONSABILIDAD PATRIMONIAL DEL ESTADO EN EL FUNCIONAMIENTO DE LA ADMINISTRACIÓN DE JUSTICIA RECONOCIDOS COMO DERECHOS HUMANOS EN EL ÁMBITO INTERNACIONAL
}

\author{
The assumptions of Patrimonial Liability of the State in the functioning of the Admin- \\ istration of Justice as Human Rights at the international level
}

Jessica Cristina Romero Michel ${ }^{1}$

\begin{abstract}
Sumario:
I. Introducción. II. Supuestos que originan la Responsabilidad Patrimonial en el funcionamiento de la administración de justicia. II.1. El error judicial. II.2. El error judicial cuando se ha sufrido privación de la libertad. II.3. El funcionamiento anormal de la Administración de Justicia. III. Tratados $y$ convenciones internacionales sobre Derechos Humanos que prevén estos supuestos IV. El error judicial y el funcionamiento de la Administración de Justicia reconocidos como Derechos Humanos en México. V. Conclusiones. VI. Bibliografía.
\end{abstract}

Resumen. En México no se encuentra regulada la Responsabilidad Patrimonial del Estado en el funcionamiento de la Administración de Justicia y los medios de control previstos en la legislación para obtener una indemnización como consecuencia de la actividad de administrar justicia nos obligan a accionar en contra de los servidores públicos, ahora con la reforma ocurrida en materia de Derechos Humanos surge la oportunidad de hacer valer esta figura como un Derecho Humano.

Es por ello que se desea destacar un tema que produce serias consecuencias, concretamente en los particulares que a diario se ven afectados ante innumerables errores $y$ deficiencias producidos por los órganos encargados de Administrar Justicia, pues aunque dice la sabiduría ancestral "errar es de humanos" la pregunta que se hace en este momento es ¿hasta qué punto estamos obligados a soportar esas fallas?

Palabras clave: Responsabilidad patrimonial, responsabilidad civil, derechos humanos, daño patrimonial, indemnización.

Abstract. In Mexico is not regulated the Patrimonial Liability of the State in the functioning of the Administration of Justice, and the means of control provided for in the legislation to obtain a repair of the damages as a result of the activity to administer justice require us to operate

\footnotetext{
1 Profesora Asociada del Instituto Universitario de Investigaciones Jurídicas de la Universidad de Colima y Profesor de la Facultad de Derecho de la misma Institución. Licenciada en Derecho por la Universidad de Colima, Especialista en Relaciones Intergubernamentales por la Facultad de Ciencias Políticas y Sociales de la Universidad de Colima, Maestra en Administración de Justicia por la Facultad de Derecho de la Universidad de Colima, y Doctora en Derecho por el Doctorado Interinstitucional en Derecho de la Asociación Nacional de Universidades e Instituciones de Educación Superior (ANUIES) adscrita a la Universidad Autónoma de Nayarit.
} 
against the public servants. Today with the reform occurred in the field of human rights the opportunity arises to assert this figure as a human right.

This is why I want to highlight an issue that produces serious consequences, in particular individuals who daily are affected before countless errors and deficiencies caused by the bodies responsible for administering justice, because although it says the ancestral wisdom "to make mistakes is human" the question in this moment is what exempt are we forced to endure these faults?

Key words: Patrimonial liability, civil liavility, human rights, patrimonial injury, damages.

\section{INTRODUCCIÓN}

El avance de las instituciones jurídicas de un Estado Democrático y Social de Derecho ha permitido que la defensa de los Derechos Humanos se desarrolle a través de mecanismos de protección internacional contenidos en los tratados internacionales, así como en su reconocimiento e incorporación cada vez más frecuente al derecho interno de los Estados.

Sin embargo, en el ámbito jurisdiccional a pesar del esfuerzo que se despliega para garantizar una serie de derechos a los particulares cuando se encuentran en un juicio, la posibilidad de que se regulen las disposiciones tendientes a tutelar el derecho a una indemnización cuando se generan daños y perjuicios provenientes de un error judicial o del funcionamiento anormal en la Administración de Justicia continua siendo ambigua. Las razones de esta situación podrán depender de obstáculos técnicos, políticos, financieros e incluso sociales, y es probable que el tema no sea prioritario en la agenda legislativa ante otras necesidades para el desarrollo de la Constitución, pero se trata de una problemática común en la conciencia social.

Así por ejemplo, en el ámbito penal tratándose de un error judicial, repugna más un condenado inocente que un culpable absuelto, en el caso del funcionamiento anormal, el retraso, la lentitud y las disfunciones producen un alejamiento de la impartición de Justicia de las personas, ya que se van desprestigiando los órganos ${ }^{2}$ ante la vista de los particulares que son los directamente perjudicados.

Es por ello que, en el presente trabajo de investigación se desea destacar un tema que produce serias consecuencias, concretamente en los particulares que a diario se ven afectados ante innumerables errores y deficiencias producidos por los órganos encargados de Administrar Justicia, pues aunque dice la sabiduría ancestral "errar es de humanos" la pregunta que se hace en este momento es ¿hasta qué punto estamos obligados a soportar esa fallas?

\footnotetext{
${ }^{2}$ El artículo $1^{\circ}$ de la Ley Orgánica del Poder Judicial de la Federación reconoce como órganos a los iguientes: a la Suprema Corte de Justicia de la Nación, el Tribunal Electoral, los Tribunales Colegiados de Circuito, los Tribunales Unitarios de Circuito, los Juzgados de Distrito, el Consejo de la Judicatura Federal, el jurado federal de ciudadanos, y los Tribunales de los Estados y el Distrito Federal en los casos previstos por el artículo 107, fracción XII, de la Constitución Política de los Estados Unidos Mexicanos y en los demás en que, por disposición de la ley deban actuar en auxilio de la justicia federal.
} 
En México, hasta la fecha, se vienen denegando las solicitudes de indemnización por error judicial o por funcionamiento anormal de la Administración de Justicia fundados en una interpretación restrictiva de la norma que regula a la Responsabilidad Patrimonial del Estado. ${ }^{3}$

Sin embargo, a partir de la reforma a la Constitución ${ }^{4}$ que expresamente extendió la tutela constitucional de los Derechos Humanos contenidos en los Tratados Internacionales y lä obligación de todas las autoridades a observarlos, es que se ha comenzado a dar importancia a este tema ${ }^{5}$ principalmente por dos razones, la primera, que los Derechos Humanos tienen un carácter intangible y cuando un Estado suscribe un tratado internacional incorporándolo a su derecho interno a través del mecanismo que la Constitución prevé para ello, asume la obligación de carácter erga omnes, que hace exigible el respeto y el sometimiento de los Derechos Humanos a todos los órganos del Estado, así como a sus servidores y funcionarios públicos.

Y la segunda obligación, consiste en que el Estado debe promover los derechos incorporados, lo que supone que el Estado debe adoptar todas las medidas legales, administrativas y jurisdiccionales con el objeto de asegurar y garantizar el respeto de los derechos, prevenir la vulneración de los mismos y eliminar todos los obstáculos que puedan impedir su ejercicio.

Al respecto la Corte Interamericana de Derechos Humanos en una interpretación a la Convención sobre Derechos Humanos estableció que: los Estados tienen, como parte de sus obligaciones generales, un deber positivo de garantía con respecto de los individuos sometidos a su jurisdicción. Ello supone tomar las medidas necesarias para remover los obstáculos que puedan existir para que los individuos puedan disfrutar de los derechos que la Convención reconoce. Por consiguiente la tolerancia del Estado a circunstancias o condiciones que impidan a los individuos a acceder a los recursos internos adecuados para proteger sus derechos constituye una violación. ${ }^{6}$

A pesar de ello, el estado mexicano continua omitiendo dar cumplimiento a la obligación que tiene de adecuar sus normas internas o de expedir las que permitan el desarrollo de los

\footnotetext{
${ }^{3}$ Ley Federal de Responsabilidad Patrimonial del Estado, cuyo fundamento se encuentra en la Constitución Política de los Estados Unidos Mexicanos, en su Título Cuarto, artículo 113, segundo párrafo, que regula a la Responsabilidad del Estado por los daños causados exclusivamente por la actividad administrativa irregular, vigente desde el $1^{\circ}$ de enero del 2004.

4 Publicadas en el Diario Oficial de la Federación el 6 de junio de 2011, mismas que entraron en vigor el 4 de octubre del mismo año.

${ }^{5}$ Ello no significa que antes no fuese importante, incluso previo a las reformas constitucionales éstos derechos podían invocarse por la vía de amparo una vez agotadas las instancias debido a la obligatoriedad de los tratados, toda vez que en nuestro ordenamiento jurídico se encuentran previstos diversos medios de control en materia civil, penal o administrativa, tanto en el ámbito federal como en el local para hacer valer el derecho de indemnización por daños, por ejemplo, la responsabilidad profesional o legal, regulada en los códigos que en materia civil de la mayoría de las entidades federativas prevén para exigir indirectamente al Estado la reparación de daños como consecuencia de la actividad de administrar justicia (promovida con mayor frecuencia en contra de los servidores públicos incluidos los adscritos al Poder Judicial, en donde es necesario sustanciar primero el procedimiento previsto en el Código de Procedimientos Civiles, en la inteligencia de que en caso de que resultaran insolventes, podría intentarse en una segunda acción la reparación de daños y perjuicios contra el Estado quien responderá en forma subsidiaria o solidaria); y la responsabilidad que tiene su sustento en el Derecho Público y que comúnmente se le denomina responsabilidad disciplinaria, en donde se encuadra a la responsabilidad administrativa prevista en el artículo 77 bis de la Ley Federal de Responsabilidades de los Servidores Públicos, que regula la figura del error judicial inexcusable derivado de la negligencia o la ignorancia del funcionario o servidor público.

${ }^{6}$ López Olvera, Miguel Alejandro. (2007). La responsabilidad patrimonial del Estado por error judicial. México: Instituto de Investigaciones Jurídicas, UNAM. p. 590.
} 
mecanismos conducentes para hacer efectiva la observancia del derecho a que se reparen los daños y perjuicios ocasionados por el error judicial y el funcionamiento anormal de la Administración de Justicia, es decir, el derecho a una indemnización. En este sentido se puede afirmar que el Estado únicamente se ha encargado de su reconocimiento, pero no los ha constituido.

Por lo tanto, la falta de reconocimiento jurídico de la Responsabilidad Patrimonial del Estado en el funcionamiento de la Administración de Justicia, trae como consecuencia por una lado, la imposibilidad legal del particular de obtener una indemnización por los daños causados por la actividad estatal a través de procedimientos ágiles y sencillos, y por otro, que la ausencia de regulación genera incertidumbre entre los usuarios de éste servicio, dando cabida a su flexibilización, atenuación, excepcionalidad e incluso corrupción.

A continuación se explicará de manera muy general los aspectos más importantes del tema y por supuesto se señalarán cuáles son los tratados y convenciones internacionales que prevén a estos supuestos como Derechos Humanos.

II. SUPUESTOS QUE ORIGINAN LA RESPONSABILIDAD PATRIMONIAL EN EL FUNCIONAMIENTO DE LA ADMINISTRACIÓN DE JUSTICIA.

El elemento por excelencia que configura a la Responsabilidad Patrimonial del Estado en el funcionamiento de la Administración de Justicia, es la falla en el servicio de impartir justicia, actividad que encuentra su fundamento en la obligación del Estado en garantizar la integridad, la eficiencia y la eficacia de la Administración de Justicia para evitar interpretaciones autoritarias y violatorias de los principios legales.

Cuando esta falla se presenta, es entonces cuando el Estado debe responder a través de una reparación que consiste en una indemnización por los perjuicios ocasionados principalmente por dos supuestos:

\section{Los daños causados por error judicial, y}

2. Los daños causados como consecuencia del funcionamiento anormal de la Administración de Justicia.

Hay legislaciones que consideran un tercer supuesto, como el caso de España y Argentina que catalogan el error judicial cuando se ha sufrido indebidamente prisión preventiva, o Colombia por la privación injusta de la libertad.

La determinación de si un supuesto entra en un categoría o en otra no es insignificante, pues aun cuando la fase de la reclamación administrativa es común en ambos supuestos, lo que se busca es indemnizar tanto por los daños provocados durante el procedimiento como de los daños ocasionados con motivo de la decisión.

\section{II.1. EL ERROR JUDICIAL}

Cuando se menciona al error se debe considerar la voluntad humana de quién lo comete, por lo tanto, se deben tener en cuenta dos elementos, el primero que corresponde al deseo, es decir, al ánimo que impulsa al acto errado y que pertenece al aspecto interno de cada individuo; y el segundo, que consiste en la producción de consecuencias derivadas de ese deseo. Y aunque ambas se confunden en un momento determinado, el Derecho sólo le con- 
cede importancia a la segunda ya que se tiene en cuenta no la voluntad de hacer algo, sino la efectiva realización del hecho que se quiso, esto es, a las consecuencias materiales y no solo la producción mental o intencional que se queda en el aspecto interno.

Según Almagro Nosete "El error supone un resultado equivocado, no ajustado a la Ley, bien porque no se haya aplicado correctamente el derecho, bien porque se hayan establecido unos hechos que no se corresponden con la realidad".

Al respecto, Mosset Iturraspe señala que para encuadrar al error judicial se le tiene que analizar desde el enfoque de cómo se generó el error, es decir, si éste es espontáneo "al cual llega el juez por sí, sin la intervención de un tercero", o si es provocado, esto es "la equivocación a la cual es llevado el juez por obra o conducta de terceros". "Así el 'error judicial' puede ser, (...) el resultado de la equivocación propia, de los conceptos falsos que se poseen, o la consecuencia de la actitud dolosa de las partes en el proceso o de un tercero".

Asimismo, el Tribunal Supremo Español en diversas sentencias ha dicho que "el error judicial debe proceder de una resolución injusta o equivocada, viciada de un error craso, patente, indubitado o incontestable, que haya provocado conclusiones fácticas o jurídicas ilógicas, irracionales, esperpénticas o absurdas, que rompan con la armonía del orden jurídico, resultando de actuaciones realizadas abiertamente fuera de los cauces legales". ${ }^{9}$

Es por ello que se considera que el error judicial procede de una decisión de los Tribunales de Justicia que incurren en una equivocación crasa, evidente, elemental y perceptible socialmente por el efecto de injusticia que producen, confundiendo los supuestos de hecho enjuiciados, aplicando con torpeza o negligencia una norma o ley manifiestamente contraria o decidiendo algo que no coincide con la ratio decidendi de la resolución y en aquellos casos que no son susceptibles de enmendarse en el marco de los recursos procesales que las leyes adjetivas prevén.

Por lo tanto, el error judicial es un error insubsanable mediante recursos ordinarios, y tiene como propósito último la reparación correspondiente por parte del Estado, sin perjuicio de la facultad de éste de repetir contra los jueces y magistrados en los casos que éstos hayan actuado con dolo o culpa grave, lo que es imprescindible demostrar es que sus daños sean ocasionados como consecuencia de la adopción de resoluciones injustas que directamente priven de bienes o derechos a una parte, o le impongan indebidamente obligaciones o gravámenes, esto es, que se haya dictado una resolución judicial manifiestamente equivocada, cuyos perjuicios causen directamente, por sí mismos un daño en los bienes del particular.

Así del análisis doctrinal de la figura del error judicial se pueden desprender las siguientes características:

1. El error se deriva de la función jurisdiccional propiamente dicha;

2. Se produce en una resolución jurisdiccional que pone fin a una controversia y después de haber agotado los recursos o medios de defensa que prevén las leyes;

\footnotetext{
7 Almagro Nosete, José, El sistema español de responsabilidad judicial, en: El Poder Judicial, Madrid, Instituto de Estudios Fiscales, 1983. Vol. I. Citado por Castro Estrada, Álvaro, Responsabilidad patrimonial del Estado, México, Porrúa, 2006. p.111.

8 Mosset Iturraspe, Jorge, El error judicial, Buenos Aires, Argentina, Rubinzal-Culzoni Editores, 2003. p. 80.

9 González Alonso, Augusto, Responsabilidad patrimonial del estado en la administración de justicia, Valencia, Tirant o Blanch tratados, 2008, p. 164.
} 
3. Cuando se produce, la conducta del juzgador carece de un fundamento objetivo, esto es, que el juzgador actúe caprichosamente, bajo su arbitrio y de esa manera vulnere los derechos fundamentales del particular;

4. Que exista culpa grave del juzgador como:

- La grave violación de la ley por negligencia inexcusable;

- Afirmación por negligencia inexcusable, de un hecho cuya existencia este excluida incontrastablemente, según los autos;

- La negación, por negligencia inexcusable, de un hecho cuya existencia resulte incontrastablemente de los autos, $\mathrm{y}$

5. Que pueda provenir de error de hecho o de Derecho, etc.

\section{II.2. ERROR JUDICIAL CUANDO SE HA SUFRIDO PRIVACIÓN DE LA LIBERTAD.}

Hay legislaciones que prevén al error judicial por privación de la libertad como un tercer supuesto dentro de la Responsabilidad Patrimonial del Estado en el funcionamiento de la Administración de Justicia, en el caso de España y Argentina lo catalogan como "error judicial cuando se ha sufrido indebidamente prisión preventiva", Colombia lo denomina "privación injusta de la libertad", en estos el supuesto se acciona cuando un individuo ha sufrido prisión preventiva y posteriormente se le absuelve o se dicta sobreseimiento quedando el particular libre por inexistencia del hecho imputado.

Y para que el Estado indemnice, la víctima deberá acreditar el perjuicio ocasionado, y la cuantía que dependerá del tiempo de privación de libertad y de las consecuencias personales y familiares que se hayan producido.

Los requisitos para que proceda la indemnización por prisión preventiva son: ${ }^{10}$

1. Que se haya sufrido prisión preventiva.

2. Que en la causa penal recaiga sentencia absolutoria o auto de sobreseimiento libre por inexistencia del hecho, es decir, que exista:

a) El elemento material, que es la inexistencia del hecho, que comprende tanto los casos de inexistencia objetiva del hecho, como los casos de inexistencia subjetiva, esto es que no hubiera sido constitutivo de delito, o bien imposibilidad de participación en tal hecho, y

b) El elemento formal, que consiste en la sentencia absolutoria o el auto de sobreseimiento libre o provisional en donde "se ha de atender al auténtico significado de la resolución pronunciada por la jurisdicción penal”. ${ }^{11}$

3. Que se hayan irrogado perjuicios al presunto inculpado, en donde únicamente tendrán cabida los perjuicios referentes a la prisión preventiva, y cualesquiera otras medidas cau-

\footnotetext{
${ }^{10}$ España: Sentencia del STS de 13 de noviembre de 200o. (Ar.2001\142).

${ }^{11}$ España: Sentencia del STS de 29 de mayo de 1999. (Ar. 7259). 
telares adoptadas, como desplazamientos para presentaciones ante el juzgado, inmovilización del vehículo, etc.

II.3. EL FUNCIONAMIENTO ANORMAL DE LA ADMINISTRACiÓN DE JUSTICIA Y SUS CARACTERÍSTICAS.

La Responsabilidad Patrimonial del Estado encuentra su fundamento en los criterios de la culpa, la lesión antijurídica y la falta del servicio, y es en este último en el que se centra el funcionamiento anormal de la Administración de Justicia.

Fernando Garrido considera que el funcionamiento anormal de la Administración de Justicia se refiere a la "marcha lenta", inadecuada o irregular de los procedimientos judiciales; de manera tal que existe este funcionamiento anormal cuando se ha producido una demora inexplicable en la solución del procedimiento, con independencia de que tal se deba a la lentitud del juzgador al dictar sentencia. ${ }^{12}$

Asimismo, Martín Rebollo enuncia que el funcionamiento defectuoso tiene como supuesto base, el retraso, la lentitud, la tardanza que es, de hecho, como lo han repetido los autores que he han ocupado del tema, un supuesto de denegación de justicia, ya que ésta tiene unas exigencias temporales y cronológicas inaplazables y absolutamente decisivas, de forma que una justicia tardía equivale en muchas ocasiones a una ausencia de justicia. ${ }^{13}$

En cambio Castro Estrada refiere que el concepto de anormalidad en el funcionamiento de la Administración de Justicia, constituye un concepto jurídico indeterminado cuya definición deberá hacerse casuísticamente por los Jueces y Tribunales. Ya que "tal denominación se refiere al hecho de que en el supuesto de una responsabilidad objetiva y directa del Estado, en el cual el criterio civilista de la culpa no es el más relevante, los hechos lesivos que puedan producirse con motivo de la actuación administrativa puede provenir, sea de un funcionamiento normal, regular, legal o ilícito, o bien, de un funcionamiento anormal, irregular, ilegal o ilícito; de manera tal que si se cumplen todos los requisitos de la responsabilidad patrimonial, deberá proceder la indemnización o reparación correspondiente".14

Es por ello, que se está ante el funcionamiento anormal de la Administración de Justicia "cuando las actuaciones procesales tengan una duración superior a la normal, dentro de lo que es una diligente tramitación del proceso". (...) En todo caso, no es suficiente para considerar la existencia de dilación indebida el simple incumplimiento de plazos, sino plazos razonables e imputables al órgano judicial. ${ }^{15}$ Todavez que no siempre que las actuaciones procesales se prolonguen dilatadamente en el tiempo se estará frente a un supuesto de Responsabilidad Patrimonial en el funcionamiento de la Administración de Justicia, porque puede darse el supuesto de que éstas se deban a que la parte demandada en el juicio principal con sus constantes actuaciones dilatorias y omisivas en la tramitación del proceso lo propicien.

\footnotetext{
${ }^{12}$ Garrido Falla, Fernando, Tratado de Derecho Administrativo, Vol 2, 11 a ed., Madrid, Tecnos, 1989, p. 292. Cit. Por Castro Estrada, op. cit., nota 7, p. 116.

${ }^{13}$ Martín Rebollo, Luis, Jueces y responsabilidad del Estado. El artículo 121 de la Constitución, Madrid, Centro de Estudios Constitucionales, 1983, p. 161.

${ }^{14}$ Castro Estrada, op. cit., nota 7, p. 114.

${ }^{15}$ Batet Jiménez, María Pilar, La responsabilidad patrimonial del Estado por el funcionamiento de la Administración de Justicia, Boletín Jurídico Español, núm. 1-12, noviembre 2002. p.7. Obtenido en la Red Mundial el 13 de enero 2007, en: http://www.derecho.com
} 
Por otra parte, el derecho fundamental a un proceso sin dilaciones indebidas es invocable en todo tipo de procesos y, asimismo, en las sucesivas fases e instancias por las que discurre el proceso, incluida la ejecución de sentencia, por lo que, es requisito necesario que con carácter previo, se hayan denunciado las dilaciones ante el órgano judicial, no siendo éste un mero requisito formal "sino que tiene como finalidad permitir a los órganos judiciales que puedan remediar las dilaciones y, de este modo, salvaguardar al carácter subsidiario del recurso de amparo" ${ }^{16}$

Así pues, el derecho a ser indemnizado por dilaciones indebidas no es en sí mismo un derecho invocable en la vía de amparo, ya que el pronunciamiento del Tribunal ha de limitarse a declarar la existencia de la lesión del derecho garantizado, y de la conexión entre tal lesión y el supuesto a la indemnización, sin perjuicio de que, a partir de ello, el lesionado procure, a través de otras vías, el resarcimiento a que se crea titulado, por lo que no debe confundirse entre la omisión de un trámite o formalidad esencial del procedimiento, de su defectuosa o insuficiente aplicación, puesto que en el primer supuesto se estaría frente a una causal de nulidad.

Así se puede mencionar como supuestos del funcionamiento anormal a los siguientes:

1. Los retardos como:

a) Meros incumplimientos o incumplimientos leves de los plazos procesalmente previstos en las leyes, $\mathrm{y}$

b) Las dilaciones indebidas o incumplimiento grave de los plazos, y pueden ocurrir:

En el momento procesal principal, es decir durante el proceso, y

En la ejecución de las sentencias.

2. El retardo punible, que es cuando el juzgador "retardare maliciosamente la Administración de Justicia después de requerido por las partes y de vencidos los términos legales" ${ }^{17}$, y

3. Denegación de justicia, que se configura cuando el juzgador "se negare a juzgar so pretexto de obscuridad, insuficiencia o silencio de la ley. (...) el cual paraliza o retarda el desarrollo de la función garantizadora de los derecho de los individuos o de la sociedad". ${ }^{18}$

\section{TRATAdOS Y CONVENCIONES INTERNACIONALES SOBRE DERECHOS HUMANOS QUE PREVÉN ESTOS SUPUESTOS.}

Como antecedente se puede mencionar que el punto de partida se localiza en la década de los años 50 cuando el error judicial por indebida prisión preventiva fue el primer supuesto de la Responsabilidad Patrimonial del Estado que fue incorporado como un Derecho Humano. Este fue regulado por la Convención Europea de Salvaguardia de los Derechos del Hombre y Libertades Fundamentales en su artículo $5^{\circ}$ inciso 5, que señalaba: “Toda persona

\footnotetext{
${ }^{16}$ Batet Jiménez, op. cit., nota 15, p. 8.

${ }^{17}$ Mosset Iturraspe, op. cit., nota 8, p. 183.

${ }^{18}$ Creus, Carlos, Delitos contra la Administración Pública, Buenos Aires, Astrea, 1981. 
víctima de un arresto o de una detención, en condiciones contrarias a las disposiciones del presente artículo, tiene derecho a una reparación".

A partir de esta disposición fue que se fueron sumando una serie de instrumentos internacionales que actualmente prevén los supuestos de la Responsabilidad Patrimonial del Estado en el funcionamiento de la Administración de Justicia, los cuales son:

- El Pacto Internacional de Derechos Civiles y Políticos de 1966, y

- La Convención Americana sobre Derechos Humanos de 1969.

Así se puede mencionar que además de instaurar o reconocer estos supuestos como Derechos Humanos, también los tratados y convenciones mencionadas establecen una serie de obligaciones que se pueden agrupar de la siguiente manera:

1. Las que hacen referencia a las obligaciones contraídas por el Estado, y

2. Las que señalan las normas referentes a la interpretación de los derechos.

III.1. LAS QUE HACEN REFERENCIA A LAS OBLIGACIONES CONTRAÍDAS POR EL ESTADO.

Las dos grandes obligaciones que se adquirieron por los Estados al suscribir estos tratados y convenciones internacionales consisten, por un lado, en la obligación de respetar los derechos reconocidos, y por el otro el deber de adecuación del ordenamiento interno conforme a las normas del tratado.

En cuanto a la obligación de respetar los derechos, el artículo $1^{\circ}$ de la Convención Americana sobre los Derechos Humanos, señala en su primer artículo que:

"Los Estados Partes en esta Convención se comprometen a respetar los derechos y libertades reconocidos en él y a garantizar su libre y pleno ejercicio a toda persona que esté sujeta a su jurisdicción, sin discriminación alguna por motivos de raza, color, sexo, idioma, religión, opiniones políticas o de cualquier otra índole, origen nacional o social, posición económica, nacimiento o cualquier otra condición social."

Así mismo el artículo 2 inciso 1, del Pacto Internacional de Derechos Civiles y Políticos previenen que:

"Cada uno de los Estados Partes en el presente Pacto se compromete a respetar y a garantizar a todos los individuos que se encuentren en su territorio y estén sujetos a su jurisdicción los derechos reconocidos en el presente Pacto, sin distinción alguna de raza, color, sexo, idioma, religión, opinión politica o de otra índole origen nacional o social, posición económica, nacimiento o cualquier otra condición social."

Disposiciones amplias, en las que el Estado que se adhiere a estas asume un compromiso, que involucra todo su desenvolvimiento, y que lo hace aplicable a toda persona que esté o pueda estar en un momento dado bajo su jurisdicción, sin efectuar ningún tipo de discriminación al respecto. 
En cuanto a la obligación de adecuar el ordenamiento interno, el artículo 2 de la Convención señala que:

"Si el ejercicio de los derechos y libertades mencionadas en el artículo $1^{\circ}$ no estuviera ya garantizados por disposiciones legislativas o de otro carácter, los Estados Partes se comprometen a adoptar, con arreglo a sus procedimientos constitucionales y a las disposiciones de esta Convención, las medidas legislativas o de otro carácter que fueran necesarias para hacer efectivos tales derechos y libertades."

De la misma forma el artículo 2 inciso 2, del Pacto Internacional de Derechos Civiles y Políticos dispone que:

"Cada Estado Parte se compromete a adoptar con arreglo a sus procedimientos constitucionales y a las disposiciones del presente Pacto, las medidas oportunas para dictar las disposiciones legislativas o de otro carácter que fueren necesarias para hacer efectivos los derechos reconocidos en el presente Pacto y que no estuviesen ya garantizados por disposiciones legislativas o de otro carácter."

Por lo que se trata de una obligación estatal que implica principalmente el accionar del poder legislativo, y que junto con el deber de respetar los derechos reconocidos, constituyen los pilares fundamentales de la protección de los Derechos Humanos.

Así estos tratados y convenciones internacionales obligan a todos los órganos estatales, y en materia de Derechos Humanos esto implica el compromiso de adecuación del derecho interno a la normativa internacional de protección, obligándose a respetar y dar eficacia a las normas en materia de Derechos Humanos, ya que el orden internacional sólo debe actuar en caso de que el orden interno no logre los objetivos indispensables para la protección de los derechos de los particulares.

III.2.LAS QUE SEÑALAN LAS NORMAS REFERENTES A LA INTERPRETACIÓN DE LOS DERECHOS.

La Convención Americana sobre Derechos Humanos establece sus propias reglas de interpretación, las cuales se encuentran contenidas en el artículo 29 y están expresadas en sentido negativo, así, señala que:

"Ninguna disposición de la presenta Convención puede ser interpretada en el sentido de: a. Permitir a alguno de los Estados Partes, grupo o persona, suprimir el goce y ejercicio de los derechos y libertades reconocidas en la Convención o limitarlos en mayor medida que la prevista en ella; $b$. Limitar el goce y ejercicio de cualquier derecho o libertad que pueda estar reconocido de acuerdo con las leyes de cualquiera de los Estados Partes o de acuerdo con otra Convención en que sea parte uno de dichos Estados; c. Excluir otros derechos y garantías que son inherentes al ser humano o que se derivan de la forma democrática representativa de gobierno, $y$ d. Excluir o limitar el efecto que puedan producir la Declaración Americana de Derechos y Deberes del Hombre y otros actos internacionales de la misma naturaleza."

Por lo que ninguna interpretación puede conducir a que un particular sea privado de un derecho que la propia Convención prescribe, esto es de analizarse ya que en materia de in- 
demnización por error judicial, el ordenamiento interno no reconoce dicha institución y por lo tanto no la aplica de manera efectiva.

En otro sentido, también se debe considerar que las reglas que establece la Convención por tratarse de un tratado sobre Derechos Humanos gozan de jerarquía constitucional, por lo que deben privilegiarse en su aplicación al momento de presentarse una cuestión relativa a este derecho.

IV. EL ERROR JUDICIAL Y EL FUNCIONAMIENTO ANORMAL DE LA ADMINISTRACIÓN DE JUSTICIA RECONOCIDOS COMO DERECHOS HUMANOS EN MÉXICO.

Como se mencionó en el apartado anterior existen diversas convenciones y tratados internacionales que se han centrado en instaurar los aspectos vinculados a los Derechos Humanos y de manera muy específica a las garantías tanto de los procesos jurídicos, como del funcionamiento de la estructura administrativa y procesal del sistema de Administración de Justicia de los Estados, y desde la década de los años 8o, la Responsabilidad Patrimonial del Estado en el funcionamiento de la Administración de Justicia en sus dos supuestos tanto por el error judicial, como por el funcionamiento anormal de la Administración de Justicia, fueron incorporados en México, ya que está adherido a la Convención Americana sobre Derechos Humanos ${ }^{19}$ conocida como el "Pacto de San José", que establece en sus artículos 10 la figura del derecho a la indemnización por error judicial, y 8 inciso 1, el plazo razonable; el Pacto Internacional de Derechos Civiles y Políticos ${ }^{20}$ que dispone en sus artículos 9 inciso 5 , el derecho de toda persona a obtener reparación cuando haya sido ilegalmente detenida; $y$ el 14 inciso 3, apartado c, el derecho de toda persona a ser juzgada en un proceso penal sin dilaciones indebidas.

$\mathrm{Y}$ aunque el legislador no las haya trasladado en forma explícita al marco legal interno, estas disposiciones internacionales se encuentran vigentes en forma operativa y obligatoria, ya que los tratados internacionales gozan de operatividad, es decir, garantizan el pleno goce y ejercicio de los derechos reconocidos como autoejecutivos, y los Estados parte están obligados en forma general a adecuar sus normas internas o a expedir las que permitan el desarrollo de prácticas conducentes para hacer efectiva la observancia de dichas garantías.

A pesar de esta obligación, en la práctica, éstos derechos no se han podido hacer valer de manera efectiva por los particulares que se han visto afectados por los daños y perjuicios causados por la actividad estatal en el funcionamiento de la Administración de Justicia debido a la ausencia de una regulación específica en la materia.

Con la extensión de la protección de los Derechos Humanos consagradas en la Constitución Federal y en los Tratados Internacionales, que en el artículo $1^{\circ}$ prescribe:

"En los Estados Unidos Mexicanos todas las personas gozarán de los derechos humanos reconocidos en esta Constitución y en los tratados internacionales de los que el Estado Mexicano sea parte, así como de las garantías para su protección, cuyo ejercicio no podrá

\footnotetext{
${ }^{19}$ México. Convención Americana de Derecho Humanos. Diario Oficial de la Federación del 9 de enero de 1981. -entró en vigor el 24 de marzo de 1981-.

${ }^{20}$ Pacto Internacional de Derechos Civiles y Políticos. Aprobado por el Senado de la República el 18 de diciembre de 1980. Adhesión de México el 24 de marzo de 1981. México. Diario Oficial de la Federación el 20 de mayo de 1981. Fe de Erratas 22 de junio de 1981.
} 
restringirse ni suspenderse, salvo en los casos y bajo las condiciones que esta Constitución establece.

Las normas relativas a los derechos humanos se interpretarán de conformidad con esta Constitución y con los tratados internacionales de la materia favoreciendo en todo tiempo a las personas la protección más amplia.

Todas las autoridades, en el ámbito de sus competencias, tienen la obligación de promover, respetar, proteger y garantizar los derechos humanos de conformidad con los principios de universalidad, interdependencia, indivisibilidad y progresividad. En consecuencia, el Estado deberá prevenir, investigar, sancionar y reparar las violaciones a los derechos humanos, en los términos que establezca la ley". ${ }^{21}$

Así como con la obligatoriedad de los Tribunales Federales de observar los Derechos Humanos que se encuentran previstos en los Tratados Internacionales, que el artículo 103, fracción I señala:

"Los Tribunales de la Federación resolverán toda controversia que se suscite: I. Por normas generales, actos u omisiones de la autoridad que violen los derechos humanos reconocidos y las garantías otorgadas para su protección por esta Constitución, así como por los tratados internacionales de los que el Estado Mexicano sea parte".

Significa que se está otorgando un derecho fundamental al particular afectado por la actividad estatal en el funcionamiento de la Administración de Justicia, es decir, podrá, una vez agotadas las instancias, promover por la vía de amparo tanto el error judicial como el funcionamiento anormal de la Administración de Justicia para obtener una reparación de los daños y perjuicios sufridos.

Y aunque si bien, antes de las reformas constitucionales éstos derechos podían invocarse por la vía de amparo debido a la obligatoriedad que los Tratados Internacionales tienen al ser suscritos y ratificados por México (principio de convencionalidad) ya que los artículos $1^{\circ}, 103$, fracción I, 107 y 133 de la Constitución Federal establecían respectivamente que todo individuo gozará de las garantías que ella otorga; que las leyes del Congreso de la Unión, que emanen de ella, y los tratados acordes a la misma, serán la Ley Suprema de toda la Unión, que los tribunales de la Federación resolverán toda controversia que se suscite por leyes o actos de la autoridad que violen las garantías individuales; $y$, las bases, los procedimientos y las formas para la tramitación del juicio de amparo. ${ }^{22}$

Con la entrada en vigor de las reformas constitucionales en materia de amparo se ha concedido certeza al particular, debido a que éstas generarán las condiciones jurídicas para que

\footnotetext{
${ }^{21}$ Decreto que reforma al artículo 94, párrafos séptimo, octavo, noveno y décimo; a los artículos 103 y 104; y al artículo 107, párrafo inicial; fracciones I y II; inciso a) de la fracción III; fracciones IV, V, VI y VII; inciso a) de la fracción VIII; fracciones IX, X, XI, XIII, XVI y XVII y la fracción XIV derogada. Publicadas en el Diario Oficial de la Federación el 6 de junio de 2011, mismos que entraron en vigor el 4 de octubre del mismo año. Disponible en: http://www.diputados.gob.mx/LeyesBiblio/pdf/1.pdf

${ }^{22}$ México. Tesis I.7o.C.46 K. DERECHOS HUMANOS, LOS TRATADOS INTERNACIONALES SUSCRITOS POR MÉXICO SOBRE LOS. ES POSIBLE INVOCARLOS EN EL JUICIO DE AMPARO AL ANALIZAR LAS VIOLACIONES A LAS GARANTÍAS INDIVIDUALES QUE IMPLIQUEN LA DE AQUÉLLOS. Semanario Judicial de la Federación y su Gaceta. Tomo XXVIII. Agosto de 2008. p. 1083.
} 
el derecho de indemnización por daños patrimoniales ocasionados por la actividad jurisdiccional se vea tutelada en forma efectiva cuando se vea vulnerado, y más aún, porque las reformas no tutelarán sólo a los actos de autoridad, sino también cuando las violaciones se den por falta de actuación de dichas autoridades, esto es, cuando se vulneren dichos derechos por la vía de la omisión propia del funcionamiento anormal de la Administración de Justicia.

A continuación se hará un análisis específico de cada una de estas disposiciones.

\section{IV.1. EL ERROR JUDICIAL}

Para este supuesto de Responsabilidad Patrimonial del Estado en el funcionamiento de la Administración de Justicia, el instrumento internacional que lo prevé como un Derecho Humano es La Convención Americana sobre Derechos Humanos, también denominada "Pacto de San José" que en su artículo 10, señala lo siguiente:

"Toda persona tiene derecho a ser indemnizada conforme a la ley en caso de haber sido condenada en sentencia firme por error judicial".

Así se puede observar que este Derecho establece una serie de consecuencias. En cuanto a las normas relativas a los derechos que intervienen en materia de error judicial se puede destacar que la finalidad de la declaración de error no puede ser otra que la de obtener una reparación por los daños y perjuicios sufridos por la declaración judicial errónea y no, a diferencia de los recursos procesales, que buscan una sustitución de los pronunciamientos de la resolución de que se trate, por lo que por la sola declaración del error se va a generar un derecho personal subjetivo, este es el derecho a obtener una indemnización.

Por lo tanto de esta disposición se puede destacar que se generan los siguientes derechos:

a) Derecho al reconocimiento del error judicial. Antes de su análisis es importante destacar que la Suprema Corte de Justicia de la Unión en una tesis aislada ${ }^{23}$ ha señalado que la eficacia del Derecho Humano debe garantizarse al particular a través del acceso ante la autoridad jurisdiccional con atribuciones legales para resolver una cuestión concreta prevista en el sistema legal.

Así, el poder público no puede condicionar o impedir el acceso a la administración de justicia, lo cual debe entenderse en el sentido de que la ley aplicable no deberá imponer límites a ese derecho, aunque sí la previsión de formalidades esenciales para el desarrollo del proceso, por lo que además de la normativa, los órganos encargados de administrar justicia deben asumir una actitud de facilitadores del acceso a la jurisdicción. Lo anterior no implica la eliminación de toda formalidad ni constituye un presupuesto para pasar por alto las disposiciones legislativas, sino por el contrario, ajustarse a éstas y ponderar los derechos en juego, para que las partes en conflicto tengan la misma oportunidad de defensa, pues la tutela judicial efectiva debe entenderse como el mínimo de prerrogativas con las cuales cuentan los sujetos. Por tanto, para lograr la eficacia del indicado derecho humano,

\footnotetext{
${ }^{23}$ México. Tesis aislada, 10a. Época, T.C.C., Semanario Judicial de la Federación y su gaceta, Libro VI, Marzo de 2012, Tomo 2, p. 1481. III.40.(III Región) 6 K (10a.).
} 
los juzgadores deben desarrollar la posibilidad del recurso judicial, esto es, eliminar formalismos que representen obstáculos para ello. ${ }^{24}$

En este sentido el derecho a pedir la declaración de error judicial ya está prevista en la Convención, pero en cuanto al desahogo del proceso en sí, debemos sujetarnos a lo previsto en el ordenamiento interno. Lo que significa que en México en el ámbito federal para poder obtener tal declaración es necesario desahogar un procedimiento administrativo previsto en la Ley Orgánica del Poder Judicial de la Federación, que regula la figura del error judicial inexcusable derivado de la negligencia o la ignorancia del funcionario o servidor público, y para el ámbito local se debe sujetar a las disposiciones que regulan el procedimiento de forma específica, que en algunos Estados ya se contemplan. ${ }^{25}$

b) Derecho a la indemnización. Como se mencionó, en la parte sustancial el derecho a la indemnización prevalece por tratarse de un Derecho Humano, y se puede atender la Convención por ser el derecho que debe imperar sobre los demás, es decir, se puede hacer uso de esta, con el objeto de encontrar una solución efectiva en la materia y por tratarse de una disposición que es más favorable. ${ }^{26}$ En cuanto al procedimiento se puede mencionar que se genera un problema, pues para exigir la reparación en el ámbito federal sólo se prevé la reparación del daño con motivo de la actividad meramente administrativa y no por la actividad jurisdiccional, además, existe un vacío legal, todavez que la disposición que sería aplicable se derogó. ${ }^{27}$

Entonces ¿cuál sería la disposición que se deberá aplicar para hacer valer este derecho?.28 Respecto del ámbito estatal, este procedimiento va a variar según las disposiciones locales ${ }^{29}$ y el modelo de la responsabilidad profesional que cada una prevea, ya sea civil o penal.

\footnotetext{
${ }^{24}$ México. Tesis aislada, 10a. Época, T.C.C., Semanario Judicial de la Federación y su gaceta, Libro VI, Marzo de 2012, Tomo 2, p. 1481. III.40. (III Región) 6 K (10a.).

${ }^{25}$ Con la entrada en vigor de la Ley Federal de Responsabilidad Patrimonial del Estado, el artículo 1927 del Código Civil que regulaba la responsabilidad extracontractual del Estado se derogó. En el ámbito local, Jalisco, Guanajuato y Baja California derogaron de sus códigos civiles la obligación que tiene el Estado de responder del pago de los daños y perjuicios causados por sus empleados y funcionarios con motivo del ejercicio de sus atribuciones, Aguascalientes prevé en el artículo 9, fracción XI de la Ley Orgánica del Poder Judicial al error judicial, Coahuila constitucionalizó esta figura jurídica en el artículo 154, párrafo IV, Chihuahua tiene la Ley para exigir responsabilidad a jueces y funcionarios del Ministerio Público, Baja California regula en el artículo 67 del Código de Procedimientos Penales el error judicial cuando es producto de la mala fe y La Constitución Política del Estado de Sinaloa en el artículo 4 Bis A, fracción XII que establece el derecho a la indemnización por indebida prisión preventiva.

${ }^{26}$ Así lo señala el artículo $1^{\circ}$ párrafo segundo de la Constitución Política de los Estados Unidos Mexicano.

${ }^{27}$ Se debe recordar que con la entrada en vigor de la Ley Federal de Responsabilidad Patrimonial del Estado, el artículo 1927 del Código Civil que regulaba la responsabilidad extracontractual del Estado se derogó.

${ }^{28}$ Véase la tesis TUTELA JURISDICCIONAL EFECTIVA. PARA LOGRAR LA EFICACIA DE ESE DERECHO HUMANO LOS JUZGADORES DEBEN DESARROLLAR LA POSIBILIDAD DEL RECURSO JUDICIAL. Tesis aislada, 10a. Época; T.C.C.; Semanario Judicial de la federación y su gaceta, Libro VI, Marzo de 2012, Tomo 2, p. 1481.

${ }^{29}$ Aguascalientes prevé el error judicial en el artículo 9, fracción XI de la Ley Orgánica del Poder Judicial, Coahuila constitucionalizó esta figura jurídica en el artículo 154, párrafo IV, Chihuahua tiene la Ley para exigir responsabilidad a jueces y funcionarios del Ministerio Público, Baja California regula en el artículo 67 del Código de Procedimientos Penales el error judicial cuando es producto de la mala fe y La Constitución Política del Estado de Sinaloa en el artículo 4 Bis A, fracción XII que establece el derecho a la indemnización por indebida prisión preventiva.
} 


\section{IV.2. EL ERROR JUDICIAL POR INDEBIDA PRISIÓN PREVENTIVA}

El Pacto Internacional de Derechos Civiles y Políticos, es el instrumento internacional que prevé el derecho de indemnización como consecuencia del error judicial por indebida prisión preventiva, en sus artículos 9 inciso 5 y 14 inciso 6, que respectivamente dicen lo $\dddot{i}$ guiente:

"Toda persona que haya sido ilegalmente detenida o presa, tendrá el derecho efectivo a obtener reparación.”

"Cuando una sentencia condenatoria firme haya sido ulteriormente revocada, o el condenado haya sido indultado por haberse producido o descubierto un hecho plenamente probatorio de la comisión de un error judicial, la persona que haya sufrido una pena como resultado de tal sentencia deberá ser indemnizada, conforme a la ley, a menos que se demuestre que le es imputable en todo o en parte el no haberse revelado oportunamente el hecho desconocido."

De su análisis se derivan una serie de Derechos que intervienen en materia de error judicial por indebida prisión, pudiéndose destacar que son varios los que pueden verse afectados al dictarse una sentencia condenatoria errónea. Sin embargo, en forma directa, puede decirse que son dos los derechos que se ven vulnerados:

a) El derecho a la libertad y a la seguridad personal. Toda vez que el artículo $7^{\circ}$ de la Convención, junto con garantizar la libertad personal, establece en siete numerales una serie de consecuencias que derivan de aquél derecho, de manera parecida a los que se establecen en los artículos 16, 18 y 19 de la Constitución Política de los Estados Unidos Mexicanos, principalmente: el derecho a la libertad y a la seguridad personales; que nadie puede ser privado de su libertad, salvo por las causas y en las condiciones previstas por la Constituciones; Nadie puede ser sometido a detención o encarcelamiento arbitrario, y

b) Derecho al reconocimiento del error judicial por indebida prisión preventiva. En este punto, como ya se mencionó en el análisis del el error judicial, las reglas son las mismas, el derecho a pedir la declaración de error judicial por indebida prisión preventiva debe sujetarse al desahogo del proceso previsto en el ordenamiento interno, y para poder obtener tal declaración para el ámbito federal es necesario desahogar un procedimiento administrativo previsto la Ley Orgánica del Poder Judicial de la Federación, y para el ámbito local se debe sujetar a las disposiciones que regulan el procedimiento de forma específica, que en algunos Estados ya se contemplan. ${ }^{30}$

c) Derecho a obtener la indemnización por la condena injusta. Como se mencionó, en la parte sustancial el derecho a la indemnización prevalece por tratarse de un Derecho Humano, y se puede acudir al Pacto mismo por ser el derecho que debe imperar sobre los demás, en cuanto a hacer valer el derecho, las reglas señalan que debe hacerse conforme a las normas internas previstas para resolver la cuestión, el problema se genera nuevamente al momento de exigir la reparación ya que la norma constitucional para el ámbito federal

\footnotetext{
$\overline{{ }^{30} \text { Véase nota no. } 29 .}$
} 
sólo prevé la reparación del daño con motivo de la actividad meramente administrativa y no por la actividad jurisdiccional, además de que existe un vacío legal todavez que la disposición que sería aplicable se derogó. ${ }^{31}$ Respecto del ámbito estatal, este procedimiento va a variar según sus propias disposiciones que en sí son distintas ${ }^{32} \mathrm{y}$ va a depender del modelo de la responsabilidad profesional que prevean ya sean dentro del ámbito sea civil o del ámbito penal.

\section{IV.3. EL FUNCIONAMIENTO ANORMAL DE LA ADMINISTRACIÓN DE JUSTICIA.}

En este supuesto operan dos instrumentos internacionales y los hacen en la vertiente de las "dilaciones indebidas" en un proceso penal, el Pacto Internacional de Derechos Civiles y Políticos que dispone en su artículo 14 inciso 3, apartado c; y la Convención Americana sobre Derechos Humanos en su artículo 8 inciso 1, que señalan respectivamente lo siguiente:

"Durante el proceso, toda persona acusada de un delito tendrá derecho, en plena igualdad, a las siguientes garantías mínimas: c) A ser juzgada sin dilaciones indebidas".

"Toda persona tiene derecho a ser oída, con las debidas garantías y dentro de un plazo razonable, por un juez o tribunal competente (...)".

De lo que se infiere que se derivan una serie de Derechos que intervienen en la materia:

a) Derecho a ser juzgado sin dilaciones indebidas. En este sentido el derecho a ser juzgado sin dilaciones indebidas está previsto en forma implícita en el artículo 17 párrafo segundo de la Constitución cuando refiere que todas las personas tienen derecho a que se les Administre Justicia "en los plazos y términos que fijen las leyes" y que las resoluciones emitidas por los órganos encargados de administrar justicia deberán "ser prontas", sin embargo, el reconocimiento que pudiera hacer un Tribunal sobre si un órgano encargado de impartir justicia incurrió o no en una dilación indebida no está previsto en ningún dispositivo, por lo que el derecho a una reparación patrimonial cuando se genere un daño como consecuencia de ésta, tampoco existe, asimismo, no hay una ley adjetiva que regule la acción y el procedimiento que se pudiera promover por los afectados para obtener dicho reconocimiento, por lo que sin ello, tampoco se podrá crear la conexión entre la lesión y el supuesto de indemnización, la vía que se podría intentar es promoviendo los medios de defensa legales correspondientes por la omisión de un trámite o formalidad esencial

\footnotetext{
${ }^{31}$ Se debe recordar que con la entrada en vigor de la Ley Federal de Responsabilidad Patrimonial del Estado, el artículo 1927 del Código Civil que regulaba la responsabilidad extracontractual del Estado se derogó.

${ }^{32}$ Jalisco, Guanajuato y Baja California derogaron de sus códigos civiles la obligación que tiene el Estado de responder del pago de los daños y perjuicios causados por sus empleados y funcionarios con motivo del ejercicio de sus atribuciones, Aguascalientes previene en el artículo 9, fracción XI de la Ley Orgánica del Poder Judicial al error judicial, Coahuila constitucionalizó esta figura jurídica en el artículo 154, párrafo IV, Chihuahua tiene la Ley para exigir responsabilidad a jueces y funcionarios del Ministerio Público, Baja California regula en el artículo 67 del Código de Procedimientos Penales el error judicial cuando es producto de la mala fe y La Constitución Política del Estado de Sinaloa en el artículo 4 Bis A, fracción XII que establece el derecho a la indemnización por indebida prisión preventiva.
} 
del procedimiento, ${ }^{33}$ y una vez agotada la instancia intentar por la vía del amparo el resarcimiento correspondiente invocando el tratado internacional.

Para este supuesto y únicamente en materia penal, el constituyente plasmó en el artículo 20, apartado B, fracción VII de la Constitución el Derecho de toda persona imputada “ä ser juzgada en un plazo máximo de cuatro meses si se le acusa de un delito cuya pena máxima no exceda de dos años de prisión; y antes de un año si la pena excediere de ese tiempo, salvo que solicite mayor plazo para su defensa." Es por ello que si una sentencia es dictada fuera de ese tiempo y durante el proceso se le causaron daños y perjuicios, entonces se está generando el derecho a la reparación patrimonial correspondiente, el problema a tratar es que en el ámbito federal y en la mayoría de los locales hay una disposición adjetiva que señale el procedimiento para poder accionar dicho derecho subjetivo.

b) Derecho a una indemnización. Derecho que se infiere, todavez que si al ser juzgado la autoridad incurre en la vulneración y con ello genera daños y perjuicios, eso por supuesto da cabida a exigir una debida reparación, pero si no hay una disposición que declare la dilación indebida, entonces se dificultará aún más poder hacer valer el derecho a una indemnización, que ya se requiere la declaración del derecho garantizado, y su conexión entre tal lesión y el supuesto a la indemnización y para tal efecto estaríamos en la misma situación que ya se analizó para el error judicial y el error judicial por indebida prisión.

Como observación adicional, se puede mencionar que el derecho fundamental a un proceso sin dilaciones indebidas en los países que ya lo han incorporado, ${ }^{34}$ es invocable en todo tipo de procesos en todas las materias legales, y asimismo, en las sucesivas fases e instancias por las que discurre un proceso, incluida la ejecución de sentencia, sin embargo en este supuesto el objeto de tutela es muy limitado ya que se refiere exclusivamente a la penal, además las dilaciones indebidas no son la única causa que origina el funcionamiento anormal de la Administración de Justicia.

\section{CONCLUSIONES}

1. El sistema de responsabilidad objetiva y directa prevista en la Responsabilidad Patrimonial del Estado supone un énfasis especial en el daño causado a un particular que no tiene la obligación jurídica de soportarlo, más allá de los aspectos de negligencia, culpabilidad o dolo del juzgador, es por ello que la Responsabilidad Patrimonial del Estado en el funcionamiento de la Administración de Justicia es una figura que es considerada como esencial en los sistemas jurídicos contemporáneos.

\footnotetext{
${ }^{33}$ La jurisprudencia desde el año 2001 ha hecho referencia a la facultad que tiene el legislador para fijar los plazos de duración de un proceso tomando en cuenta lo que ordena la Constitución. Véase el criterio del pleno de la 9a. época, publicado en Semanario Judicial de la Federación y su Gaceta, Tomo XIV, Septiembre de 2001. p. 5. JUSTICIA ACCESO A LA. La potestad que se otorga al legislador en el artículo 17 de la Constitución general de la república, para fijar los plazos y términos conforme a los cuales aquélla se administrará no es ilimitada, por lo que los presupuestos o requisitos legales que se establezcan para obtener ante un tribunal una resolución sobre el fondo de lo pedido deben encontrar justificación constitucional.

34 Por citar algunos ejemplos se encuentra España en la Constitución artículos 117.1 y 121, así como en la Ley 6/1981 Orgánica del Poder Judicial en su título V, y la Ley 30/1992 del Régimen Jurídico de las Administraciones Públicas y del Procedimiento Administrativo Común, modificada por la Ley 4/1999; Francia en la Ley Orgánica sobre el Estatuto de la Magistratura.
} 
2. Aunque el error judicial y el funcionamiento anormal de la Administración de Justicia en materia penal están consagrados como Derechos Humanos, debido a que se encuentran previstos en las disposiciones internacionales suscritas y ratificadas por nuestro país desde los años ochenta, en la legislación mexicana se cuenta con alternativas muy diversas dependiendo del ámbito de competencia para hacer valer el derecho a una indemnización.

3. Así, la ausencia de disposiciones específicas sobre Responsabilidad Patrimonial del Estado en el funcionamiento de la Administración de Justicia, ha propiciado un estado de vulnerabilidad para el particular, especialmente frente al error judicial por indebida prisión, pues una vez que éste se enfrenta al sistema y es sobreseído el asunto o declarado inocente mediante la revocación de una sentencia dictada erróneamente, se busca reparar los daños y perjuicios ocasionados por el Estado y debido a la falta de ésta normas es que no se ha podido otorgar una debida reparación lo que conlleva a una vulneración de este derecho.

4. Es por ello que se considera que debería extenderse el alcance de la Responsabilidad Patrimonial del Estado al funcionamiento de la Administración de Justicia, como parte del cumplimiento de la obligación que el Estado adquirió al adherirse a la Convención Americana sobre Derechos Humanos y el Pacto de Derechos Civiles y Políticos, pues debe adoptar todas las medidas legales, administrativas y jurisdiccionales con el objeto de asegurar y garantizar el respeto al derecho a obtener una indemnización con motivo del error judicial y del funcionamiento anormal de la Administración de Justicia.

VI. BIBLIOGR AFÍA

ACOSTA GALLO, Pablo, La responsabilidad del estado-juez. Error judicial y funcionamiento anormal de la administración de justicia, Madrid, Montecorvo, S.A., 2005.

BATET JIMÉNEZ, María Pilar, "La responsabilidad patrimonial del Estado por el funcionamiento de la Administración de Justicia”, Boletín Jurídico Español, núm. 1-12, noviembre 2002. Obtenido en la Red Mundial el 13 de enero 2007, en: http://www. derecho.com

CASSAGNE, Juan Carlos, Derecho administrativo, $4^{\mathrm{a}}$ ed., Buenos Aires, Abeledo- Perrot, 1993.

CASTRO ESTRADa, Álvaro, Nueva garantía constitucional. La responsabilidad patrimonial del Estado, México, Porrúa. 2002.

CASTRO ESTRADA, Álvaro, Responsabilidad patrimonial del Estado, México, Porrúa, 2006.

CREUS, Carlos, Delitos contra la Administración Pública, Buenos Aires, Astrea, 1981.

DELGADILLO GUTIÉRREZ, Luis Humberto, El sistema de responsabilidad de los servidores públicos, México, Porrúa, 1998.

GARCÍA DE ENTERRÍA, Eduardo y Tomas-Ramón FERNÁNDEZ, Curso de derecho administrativo II, $3^{\text {a }}$ ed., Madrid, Civitas, 1991. 
GARCÍA PONS, Enrique, Responsabilidad del Estado: la justicia y sus límites temporales, Barcelona, José María Bosch Editor, S.L., 1997.

GONZÁLEZ ALONSO, Augusto, Responsabilidad patrimonial del estado en la administración de justicia, Valencia, Tirant o Blanch tratados, 2008, p. 164.

LÓPEZ OLVERA, Miguel Alejandro, La responsabilidad patrimonial del Estado por error judicial, México, Instituto de Investigaciones Jurídicas, UNAM, 2007.

MARÍN GONZÁLEZ, Juan Carlos, La responsabilidad patrimonial del Estado, México, ITAM-Porrúa, 2004.

MARROQUÍN ZALETA, Jaime Manuel, El error judicial inexcusable como causa de responsabilidad administrati administrativa. Conferencia magistral dictada por el Consejero Jaime Manuel Marroquín Zaleta en las extensiones del Instituto de la Judicatura Federal de Ciudad Victoria, Tamaulipas, y Monterrey, N.L., México, Suprema Corte de Justicia de la Nación, 2001, Colección discursos No. 16.

MARTÍN REBOLLO, Luis, La responsabilidad patrimonial de la administración en la jurisprudencia, España, Civitas, S. A., 1977.

MARTÍN REBOLLO, Luis, Jueces y responsabilidad del Estado. El artículo 121 de la Constitución, Madrid, Centro de Estudios Constitucionales, 1983.

MOSSET ITURRASPE, Jorge, El error judicial, Buenos Aires, Argentina, Rubinzal-Culzoni Editores, 2003.

RENTERÍA, Adrián, Discrecionalidad judicial y responsabilidad, Doctrina Jurídica Contemporánea, México, Universidad de Chihuahua y Distribuciones Fontamara, 2001.

SALOMONI, Jorge, Originalidad del fundamento de la responsabilidad del Estado en Argentina. (Alcances y régimen jurídico con especial referencia a la extracontractual)". Buenos Aires, Argentina: Bs. As., 1999. Vedel, Georges, Derecho administrativo, trad. de Rincón Jurado, Juan, Madrid, Biblioteca Jurídica Aguilar, 1980.

Convención Americana sobre Derecho Humanos. México. Diario Oficial de la Federación del 9 de enero de 1981.

Convención Europea de Salvaguardia de los Derechos del Hombre y de las Libertades Fundamentales.

Pacto Internacional de Derechos Civiles y Políticos. Aprobado por el Senado de la República el 18 de diciembre de 1980. México. Diario Oficial de la Federación el 9 de enero de 1981.

México. Constitución Política de los Estados Unidos Mexicanos. 2012. Anaya Editores, S. A. México. Código Civil Federal. México. Compila. Legislación Federal y del Distrito Federal. Poder Judicial de la Federación. Suprema Corte de Justicia de la Nación.

México. Código Federal de Procedimientos Civiles. Compila. Legislación Federal y del Distrito Federal. Poder Judicial de la Federación. Suprema Corte de Justicia de la Nación.

México. Código Federal de Procedimientos Penales. Compila. Legislación Federal y del Distrito Federal. Poder Judicial de la Federación. Suprema Corte de Justicia de la Nación. 
México. Código Penal Federal. México. Compila. Legislación Federal y del Distrito Federal. Poder Judicial de la Federación. Suprema Corte de Justicia de la Nación.

México. Ley Federal de Responsabilidades de los Servidores Públicos. Compila. Legislación Federal y del Distrito Federal. Poder Judicial de la Federación. Suprema Corte de Justicia de la Nación.

México. Ley Federal de Responsabilidad Patrimonial del Estado. Obtenido en la Red Mundial el 7 de mayo de 2011: http://www.juridicas-unam.mx

México. Ley Orgánica del Poder Judicial de la Federación. Compila. Legislación Federal y del Distrito Federal. Poder Judicial de la Federación. Suprema Corte de Justicia de la Nación.

España. Constitución Española. Artículos 106.2 y 121. España. Obtenido en la Red Mundial el 7 de mayo de 2011: http://noticias.juridicas.com

España. Ley Orgánica 6/1985, de 1 de julio, del Poder Judicial. Artículos 292 a 297. España. Obtenido en la Red Mundial el 7 de mayo de 2011:

http://noticias.juridicas.com/base_datos/Admin/lo6-1985.13t5.html

España. Ley 30/1992, de 26 de noviembre, de Régimen Jurídico de las Administraciones Públicas y del Procedimiento Administrativo Común, modificada por la Ley 4/1999, de 13 de enero. España. Obtenido en la Red Mundial el 7 de mayo de 2011: http://noticias. juridicas.com

España. Real Decreto 429/1993, de 26 de marzo, que aprueba el Reglamento de los Procedimientos de las Administraciones Públicas en materia de responsabilidad patrimonial. España. Obtenido en la Red Mundial el 7 de mayo de 2011: http://noticias.juridicas. com 